\title{
Assessment of suicide risk
}

\author{
Louis Appleby
}

A century of suicide research has confirmed what Durkheim told us - that the main influences on suicide rates are social (Durkheim, 1952 original publication, 1897). The evidence for the effectiveness of clinical services in reducing suicide, on the other hand, is almost totally lacking. Even the much-quoted findings from the Gotland study, in which brief training for general practitioners in the management of depression was followed by a temporary fall in the island's suicide rate (Rutz et al, 1989), have to be seen as preliminary at best. Although the suicide rate fell substantially, the numerical change was small a difference of 10 cases between the years immediately pre- and post-training - the kind of change that occurs by random fluctuation in areas of small population.

But it would be wrong to hide behind this absence of research findings and resign ourselves to the futility of suicide prevention in clinical practice. After all, the problems for research are primarily methodological and concern the use of suicide as an outcome measure within the lifetime of a study suicide is an uncommon event in any one locality. Social factors have been equally important in the prevention of mortality from tuberculosis, diphtheria and cholera but no-one doubts the clinical value of antibiotics, immunisation and intravenous fluids. Making clinical practice safer is desirable and achievable, and strategles that protect individuals at risk are self-evidently worthwhile; whether or not suicide rates are seen to fall as a result is a separate and more complex issue.

So Gethin Morgan is right to stress in this issue of the Bulletin that we should aim to prevent suicide by improving the ability of services to recognise, assess and manage people at risk. In our study of suicides by people aged under 35 in Greater Manchester, we found that as the time of suicide approached subjects of both sexes increasingly attended their GPs (Appleby et al, 1996). In the final week before death, $15 \%$ consulted a GP - a $15 \%$ reduction in the population suicide rate is a key Health of the Nation target (DoH, 1992). Although two-thirds of the final consultations were for psychological reasons, it was unusual for any impression of suicide risk to be recorded in the casenotes: this occurred in only two of 61 subjects, and in both cases risk was thought to be insignificant. This is not to point the finger at GPs because, as Morgan says, suicides that are prevented do not feature in studies like this. But it does suggest that accurate risk assessment is one potential route to suicide prevention. If so, we need a large-scale training programme for health service staff who are in contact with high-risk individuals.

This is particularly true in mental health services. In our study of suicides following discharge from in-patient psychiatric care, the expression of suicidal ideas during after-care was the strongest predictor of suicide (Dennehy et al, 1996). As in the GP contact study, there had been an opportunity for prevention through risk assessment. Even so, almost half the suicides were not noted to have had suicidal ideas, suggesting that some people indicate their risk in less direct ways, e.g. through increasing use of alcohol, hostility, etc., whose significance may not be picked up. Less than one-third of suicides had an identifiable key worker, the essence of the Care Programme Approach. further evidence that our ability to recognise who is at risk is insufficient.

Why should this be when the risk factors for suicide are widely known? I think there are three reasons. Firstly, the risk factors in the population may not be applicable to groups such as people with mental illness. Mental illness itself is a powerful risk factor, capable of obliterating the effect of other variables. Even the preponderance of males, one of the most consistent findings in suicide research, is much less apparent in the mentally ill. In our after-care study, variables such as living alone, marital status and unemployment were equally common in suicides and controls matched for age, gender and diagnosis.

Secondly, assessment of suicide risk that is based on risk factors alone ignores the fact that risk is a balance between risk factors and protective factors. Although we know little about the latter, it seems likely that social support and specific aspects of mental health care such as the availability of services would be examples. According to the risk/protective factor model, a person with numerous risk factors may not be at high risk if each is counterbalanced. Similarly, a patient whose clinical condition is stable may become high risk because the care they receive is 
reduced. For example, we know that suicides cluster in the immediate post-discharge period a time of apparent recovery. In our after-care study, 33\% of suicides occurred within 3 months of leaving hospital - a 33\% reduction is the Health of the Nation (DoH, 1992) target for suicide in severe mental illness - half of these before the first follow-up appointment.

Thirdly, the risk factor approach treats suicide as an event when in reality it is the end-point of a sequence of events. A patient leaves hospital, stops his medication, becomes depressed and starts drinking; his wife leaves him and he kills himself. Marital break-up is the terminal event but the evidence of increasing risk may go back months. Identifying such models of cumulative risk, each with different opportunities for prevention, is now a priority for our research.

One source of evidence will be the National Confidential Inquiry into Suicide and Homicide by People with Mental Illness. In the first three months following its move to Manchester, the Inquiry has received notification of more than 1000 suicides in England, a figure that should translate into at least 250 cases under mental health care. Over the next few years the large volume of detailed clinical data will form the basis of recommendations for service develop- ment and training. In this way we hope to reduce avoidable deaths from suicide, whatever happens to overall suicide rates.

\section{References}

APPLEBY, L., AMOS, T., DOYLE, U., et al (1996) General practitioners and young suicides; is there a preventive role for primary care? British Journal of Psychiatry, 168, 330-333.

DENNEHY, J. E., APPLEBY, L., ThOMAs, C. S., et al (1996) A case control study of suicide by discharged psychlatric patients. Brttish Medical Journal, 312, 1580.

DEPARTMENT OF HEALTH (1992) The Health of the Nation. London: HMSO.

DURKHEIM, E. (1952) Suicide (Translated by J. A. Spaulding \& G. Simpson). London: Routledge \& Kegan.

MORGN, G. (1997) Management of sulcide risk. Psychtatric Bulletin, 21, 214-216.

RUTZ, W., VON KNORRING, L. \& WOLINDER, J. (1989) Frequency of suicide on Gotland after systemic postgraduate education of suicide practitioners. Acta Psychilatrica Scandinavica, 80. 151-154.

Louis Appleby, Director, National Confidential Inquiry into Suicide and Homicide by People with Mental Illness, School of Psychiatry \& Behavioural Sciences, Untwersity of Manchester, Withington Hospital, Manchester M20 8LR 